Sharif University of Technology
Scientia Iranica
SCIENTIA
I RAN I CA
http://scientiairanica.sharif.edu

\title{
Optimization of embedded rail slab track with respect to environmental vibrations
}

\author{
M. Esmaeilia ${ }^{a, *}$, M. Yaghini ${ }^{\mathrm{b}}$, and Sh. Moslemipour ${ }^{\mathrm{b}}$ \\ a. Center of Excellence for Railway Transportation, Iran University of Science and Technology, Narmak, Tehran, P.O. Box \\ 16846-13114, Iran. \\ b. School of Railway Engineering, Iran University of Science and Technology, Tehran, Iran.
}

Received 15 January 2017; received in revised form 15 October 2017; accepted 22 October 2018

KEYWORDS
Optimization;
Embedded slab track
rail system;
Trough geometry;
Elasticity modulus;
Surrounding
materials;
Vibration
environmental;
Design of experiments.

\section{KEYWORDS}

rail system;

Trough geometry;

Elasticity modulus;

Surrounding

Vibration

Design of experiments.

\begin{abstract}
This paper aims to select trough geometry (width and height) and surrounding elastic materials (elasticity modulus) as optimization parameters and, also, chose minimum environmental vibrations at the critical point of the pavement system. The optimum trough geometry and specifications of surrounding materials were evaluated as part of the objective function. In doing so, a numerical finite element model of the embedded slab track rail system was developed with regard to the components of the substructure and superstructure of the system under plain strain conditions. In the first step, the numerical model was calibrated by comparing its results with static lab results. In the next step, the vibration behavior was investigated after applying a harmonic load to the system at various amplitudes and frequencies corresponding to the real operation conditions. Maximum velocity of particles' vibrations was evaluated at different points in the vertical direction, and the critical point of the pavement system was determined. Then, the best trough section and elasticity modulus of surrounding materials corresponding to the load amplitude and frequency were determined by designing experiments using the surface response method and limiting the maximum vibrations of critical points to 65 decibels.
\end{abstract}

(C) 2020 Sharif University of Technology. All rights reserved.

\section{Introduction}

Factors such as life-cycle cost, construction period, availability, and durability play an important role in designing rail lines. This issue has gained much significance lately due to the increased traffic and travelling speed. Other points relating to the development of rail transport within the cities, which should be considered, include vibration noise and the resultant complaints of people residing adjacent to these tracks. Therefore, it

\footnotetext{
*. Corresponding author.

E-mail addresses: M_esmaeili@iust.ac.ir (M. Esmaeili);

Yaghini@iust.ac.ir (M. Yaghini); sh_moslemi@engineer.com (Sh. Moslemipour)
}

doi: $10.24200 /$ sci. 2018.21077 is quite essential to deal with these problems existing in populated urban areas with surface tracks or inside low-depth tunnels.

As previously pointed out, the demand for less maintenance works has drawn ever-increasing attention to the ballast-less track systems. Suitable loading capacity and durability of the geometrical parameters are among the advantages of these tracks. However, the biggest disadvantages of these systems are their higher vibration level and high construction cost. Some improvements have been made in ballast-less systems lately in order to reduce the noise and vibration emission in particular.

One of the ballast-less track types with continuous supports and concrete slabs is the embedded rail slab track. This system has a variety of forms, which are suitable for various types of rail transport. The 
development of the Embedded Rail System (ERS) commenced in early 1960 in the Netherlands and continued until the technological advances resulted in the production of the continuous supports for embedded slab track systems. Although the ERSs have similar performance to other types of rail system, they have made a significant progress for particular applications. These systems provide more opportunities to implement a complete and advanced plan besides a more effective maintenance plan, which are the reasons why the processes in the construction industry have focused on them [1].

In recent years, various studies have been undertaken on ERSs. In 1988, K.H. Oostermeijer evaluated the dynamic behavior of this system in high-speed tracks [2], while R.M. Siderius investigated the possibility of using expanded poly styrene as sub-base material for ERSs [3]. Further, in 1988, projects entitled "silent traffic of trains" involving the design of particular embedded tracks along with compatible profiles, which were intended to reduce the noise, were evaluated and launched [4]. During 2001-2005, a study was conducted on the application of Asphalt [5] in these systems in order to develop ERSs. In another research in 2001, the elastic behavior of the ERS was investigated through lab experiments [6]. However, a study was undertaken with the objective of optimizing the ballast-less track systems during 1999-2003 by Esveld et al. (2003) [7]. In this project concerning the emitted noise, maintenance tasks and volume of the elastic compound of ERS were optimized. In this research, static modeling of ERS was carried out by ANSYS software, while dynamic modeling was performed with RAIL software and the optimization process with IMOPT software using MARS method. For an optimized design of ERS, three principal constraints of lateral displacement, structural strength of elements, and lateral buckling of tracks were considered [6].

After a careful review of technical literature, one can say that the optimization of rail seat (trough) dimensions and elastic surrounding materials as a function of applied load amplitude and frequency with the aim of limiting the environmental vibrations is an important issue, which has not been considered yet. Therefore, this research aims to select trough geometry (width and height) and surrounding elastic materials (elasticity modulus) as optimization parameters. By selecting minimum environmental vibrations as a critical point of the pavement system as part of the objective function, the most optimum trough dimensions and surrounding elastic materials are evaluated. A 2D finite element model of the embedded slab track rail system was developed under plain strain conditions, composed of pavement and bedding elements of the system. In the first step, the numerical model was calibrated by comparing its results with the static lab results. In the next step, harmonic loads were applied to the system at various amplitudes and frequencies corresponding to the actual operation conditions, and maximum vibration speed of particles at different points in the vertical direction was determined along with the critical pavement point. Then, Response Surface Method (RSM) algorithm was used for selecting the best trough section and elasticity modulus of surrounding materials corresponding to the load amplitude and frequency by limiting the maximum vibrations of critical points to 65 decibels.

\section{Development of a numerical finite element model for analyzing the static behavior of ERSs}

In this section, a 2D finite element model of the embedded slab track rail system composed of UIC54 rail and surrounding elastic compound was developed in order to compare its results with those of the research undertaken by Esveld et al. (2003) [7] using ABAQUS software. In the next section, more details of the ERS relating to bedding and pavement will be added to the model in order to evaluate its behavior under dynamic loads.

In the research undertaken by Esveld et al., UIC54 rail embedded in an elastic compound was used. Geometrical specifications and elastic compound are given in Table 1. Elasticity modulus of the rail and Poisson's ratio are $2 \times 10^{5} \mathrm{~N} / \mathrm{mm}^{2}$ and 0.3 , respectively. Moreover, elasticity modulus of the rail and Poisson's ratio of the compound are $5.6 \mathrm{~N} / \mathrm{mm}^{2}$ and 0.46 , respectively.

Supports are positioned on both sides and below the elastic compound to block any movements in the horizontal and vertical directions and rotations about $Z$ axis. Various mesh sizes were used, and the maximum mesh size was $50 \mathrm{~mm}$. Figure 1 shows the discretization of the rail and elastic surrounding materials along with the conditions applied to support constraints.

Given the intended conditions in the research undertaken by Esveld et al. [7], two static load types were applied to the model. These loads are applied in order to obtain the static response values of the structure for evaluating the ERS design. In the first problem,

Table 1. Comparison of the results of numerical analysis and Ref. [6].

\begin{tabular}{ccc}
\hline Parameter & $\begin{array}{c}\text { Referenced numerical Current research } \\
\text { model [6] }\end{array}$ & \begin{tabular}{c} 
model \\
\hline$U_{x}(\mathrm{~mm})$
\end{tabular} \\
$\sigma(\mathrm{Pa})$ & 1.83 & 1.86 \\
$P_{\text {buckl }}(\mathrm{MN})$ & 1071470 & 1100268 \\
\hline
\end{tabular}




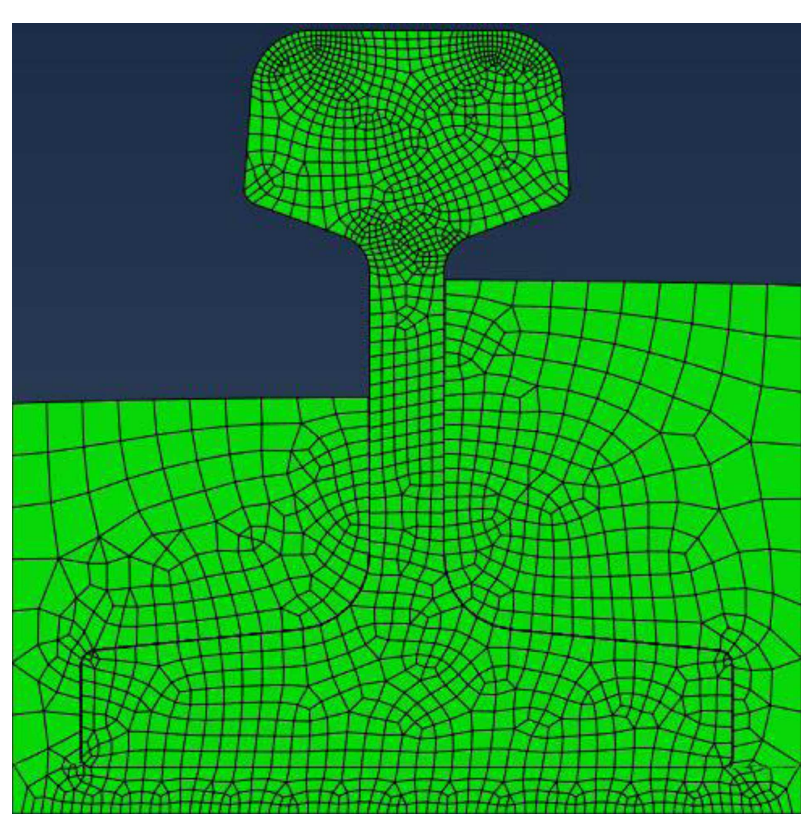

Figure 1. Finite element discretization of the embedded rail system.

a $12.2 \mathrm{kN}$ horizontal load and $30.4 \mathrm{kN}$ vertical loads were applied at a level of $0.5 \mathrm{~m}$ of the rail. In order to optimize the lateral displacement of the rail $U x$, maximum stresses (von Mises) of the elastic compound should be less than the allowable values. In this case, $U x_{\text {,allow }}=0.002 \mathrm{~m}$ and maximum tensile stress in each point of the compound should be less than $\sigma_{\text {allow. In }}$ the second question, the upward buckling of rail $\mathrm{p}_{\text {buckl }}$ was evaluated. Upward buckling occurs when there is no cohesion and connection between the rail and elastic compound. In order to control the upward buckling, an upward vertical load of $10 \mathrm{kN}$ was applied to the rail crest [6].

Table 1 shows lateral displacement and maximum stress values with the buckling force resulting from the research model and existing model in the aforementioned reference. As can be seen, the results are in good agreement with each other except for some negligible differences. Hence, it can be implied that the current numerical model may be developed as a valid model for the evaluation of the vibration behavior of ERS in the next section.

\section{Development of a numerical finite element model for the vibration analysis of the ERS}

In this section, substructure and superstructure elements of the ERS are added to the previous model; then, the vibration behavior is evaluated under $2 \mathrm{D}$ plain strain conditions after applying a harmonic load to the model. In this model, the ERS comprises SA42 rail, elastic compound, concrete slab, continuous concrete layer, hydraulically bonded layer, frost protection layer, and sub-grade, which will be considered in the following section in detail.

\subsection{Element geometry and discretization}

In this section, the substructure and superstructure elements of the ERS are added to the model. As can be seen in Figure 2, these elements are embedded in an elastic compound. Considering the common sections of embedded rails, width and height of this compound were obtained from CROW (2001) guidelines. In the structure of embedded rail, concrete slab is positioned on a concrete layer of sufficient strength. Other bedding layers include the hydraulically bonded layer and frost protection layer to be placed on sub-grade layer with a density of $98 \%$ and elasticity modulus of 45 $\mathrm{N} / \mathrm{mm}^{2}$ [7]. Figure 3 shows the lay-out of the bedding and pavement system of the embedded rail, and Table 2 shows the specifications of the system components. The mesh size in all elements is $50 \mathrm{~mm}$ and is 100 $\mathrm{mm}$ in the sub-grade layer. The model is considered as 2D under plain strain conditions. There are some roller supports on the left side of the model, which prevent the movement along $X$ axis ad rotation about $Y$ and $Z$ axes. Moreover, the movement and rotation of dampers below and to the right of the subgrade layer along and about all axes are constrained. All elements are completely tied together.

\subsection{Harmonic loading resulting from the train pass}

Considering the investigations made, it is revealed that one of the trains used in the ERS is a Thalys highspeed train with a speed rate of $223-314 \mathrm{~km} / \mathrm{h}$. This train is comprised of 2 locomotives and 8 carriages with a total length of $200.18 \mathrm{~m}$. The locomotives have two bogies and four axles. The carriage that is connected to locomotive has only one joint bogie with the next carriage, and other six carriages share the other two

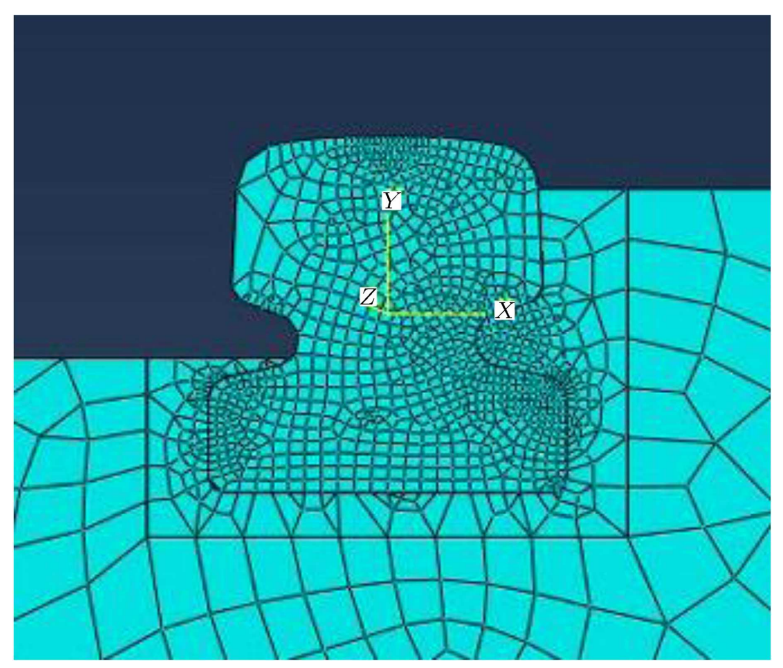

Figure 2. SA42 rail and elastic compound in ABAQUS. 


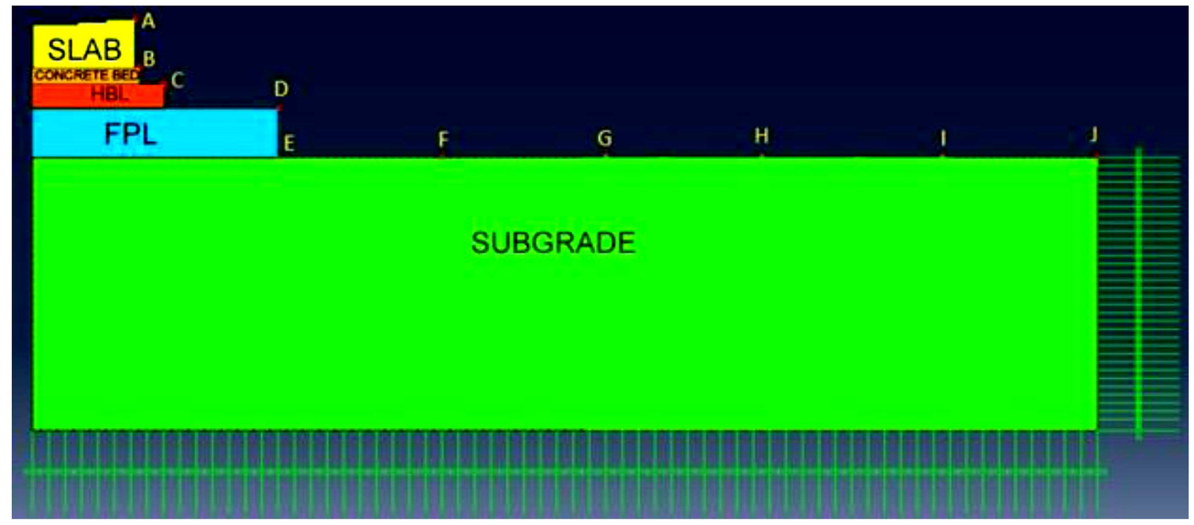

Figure 3. Lay-out of embedded rail system in ABAQUS.

Table 2. The specifications of the system components [6].

\begin{tabular}{cccccc}
\hline Track elements & $\begin{array}{c}\text { Density } \\
\left(\mathbf{k g} / \mathbf{m}^{\mathbf{3}}\right)\end{array}$ & $\begin{array}{c}\text { Elasticity modulus } \\
(\mathbf{M P a})\end{array}$ & $\begin{array}{c}\text { Poisson's } \\
\text { ratio }\end{array}$ & $\begin{array}{c}\text { Width } \\
(\mathbf{m m})\end{array}$ & $\begin{array}{c}\text { Thickness } \\
(\mathbf{m m})\end{array}$ \\
\hline RailSA42 & 7850 & $2 \times 10^{5}$ & 0.3 & 80 & 80 \\
Elastic compound & 1000 & $1-10$ & 0.46 & $160-220$ & $110-200$ \\
Concrete slab & 2400 & $3 \times 10^{4}$ & 0.2 & 1250 & 600 \\
Concrete layer & 2400 & $3 \times 10^{4}$ & 0.2 & 1300 & 200 \\
Hydraulically Bonded Layer (HBL) & 2300 & $10^{4}$ & 0.2 & 1600 & 300 \\
Frost Protection Layer (FPL) & 1800 & 120 & 0.35 & 3000 & 600 \\
Subgrade & 1700 & 45 & 0.4 & 13000 & 3400 \\
\hline
\end{tabular}

bogies with each other. This train has 13 bogies and, thus, 26 axles. Moreover, the wheel load of this train ranges from 1.5 to $9 \mathrm{kN}$ with a load frequency of 5 to $250 \mathrm{~Hz}[8]$.

In this research, harmonic loads were applied to the model with an amplitude and a frequency similar to those of the Thalys train at the center of the rail crest (Figure 4). Wheel loads are assumed to be 1.5, 5, and 9 tons. Load frequencies are 10, 20, 35, $50 \mathrm{~Hz}$, and more. Sensitivity analysis was carried out for these loads. The necessary time for conducting sensitivity

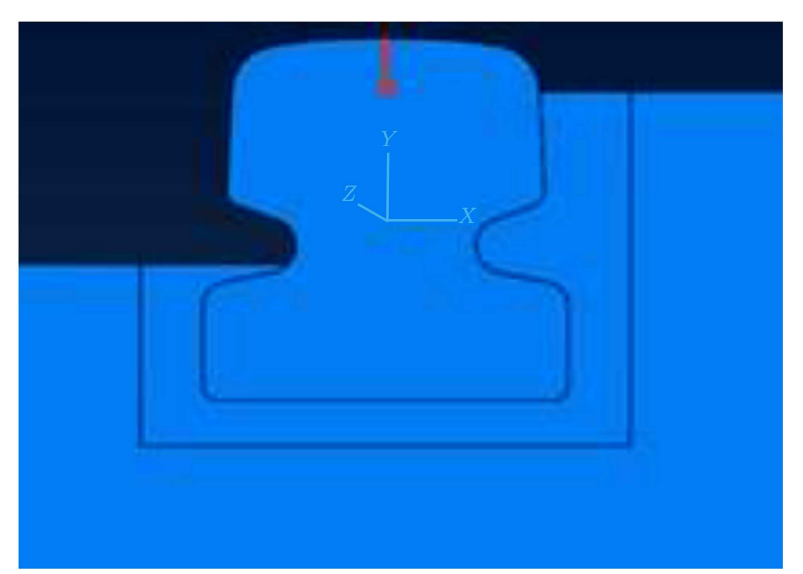

Figure 4. Vertical loading in ABAQUS software. analysis of applied loads and frequencies is 2 seconds (Figure 5) [8].

\subsection{Determining the point with critical vibrations in the pavement system}

In order to identify the critical points of the system, a sensitivity analysis was carried out for 5, 9 ton loads with a loading frequency of $10 \mathrm{~Hz}$. The loading time was assumed to take 2 seconds. Results of the analysis were obtained as the vertical vibration speed in points A to J. Results of the vibration speed are recorded on the edges of the model, concrete slab, concrete layer, hydraulically bonded layer, frost protection layer, and

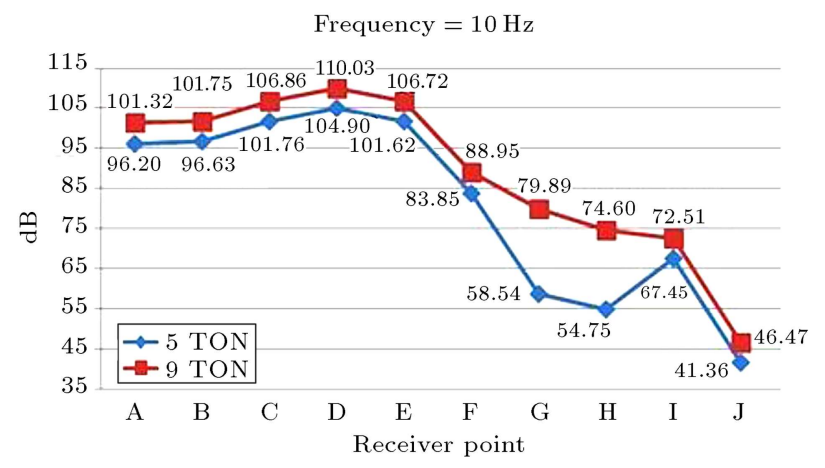

Figure 5. Evaluation of the sensitivity analysis results at points A to J. 
at $2 \mathrm{~m}$ distances on the sub-grade layer, as shown in Figure 4. The maximum speed is determined in each point, which is calculated using vibration decibel in Eq. (1) at these points. Results of these analyses are given for points $\mathrm{A}$ to $\mathrm{J}$, as shown in Figure 5 .

$$
d B=20 \times \log _{10} \frac{V_{2}}{V_{1}} .
$$

In this equation, $V_{1}$ and $V_{2}$ are the reference speed and speed at the point, respectively. The reference speed is selected from the existing codes, which is $10^{-8} \mathrm{~m} / \mathrm{s}[9]$, in this case.

As can be seen in Figure 5, the vibration decibel and vibration velocity increase with the load at a constant frequency. The peak point in both loading cases was at point $\mathrm{D}$, located on FPL layer. This increasing trend continues to point $\mathrm{E}$, which is the intersection of FPL and sub-grade layer, and then declines. Therefore, most vibrations primarily occur at point $\mathrm{D}$ and, then, at point $\mathrm{E}$, which are located on FPL and the contact point of this layer with a subgrade. These points were considered as critical points of the system in these studies. Then, the most optimum trough dimensions and the most suitable elasticity will be recommended for the surrounding rail materials with the aim of minimizing the vibrations at these points and limiting them to maximum allowable values.

\section{Introduction of the design method of experiment for the vibration optimization of the pavement system}

Design experiment method is a useful method by which key variables affecting the intended quality specifications could be identified. By using this method, one can change the controllable input factors systematically and evaluate their effect on the parameters of output product. Experiments that are designed by statistics may significantly reduce variations in the quality specifications. They also determine the level of controllable variables that optimize the process performances. Design Of Experiments (DOEs) is one of the main quality control methods prior to production, which is often used in the developmental activities and initial production stages. The design technique of experiments was developed during 1920-1930 by Ronald A. Fisher at Rothamsted Experimental Station, which is an agricultural research station located north of London [10].

The algorithm used in this section is based on the DOE method and uses the RSM, which is an effective tool for determining the response of multiple variables simultaneously, optimizing vibrations, and utilizing limited resources and data along with a suitable DOEs. In fact, this algorithm is aimed at determining the best response for resolving a problem with the minimum number of trial-and-error cases. Scientists often perform tests to explore facts relating to a system or process in order to recognize phenomena. Performing tests would always involve time and costs. Hence, performing effective tests leading to the finding of maximum data and information with minimum costs in the shortest time is the goal of every scientist or researcher [11].

Some other studies have also been undertaken using the design experiment in civil engineering such as concrete strength analysis using this method and the neural network [12]. In 2000, researchers designed an experiment for evaluating the interaction that reduces water content and anti-wash mixture for a highperformance cement grout [13]. In 2002, the role of temperature and the ending level in the prediction of tool wear was evaluated using neural networks and design experiment [14]. In 2007, key parameters that affect the reinforcement of ballast geo-grids for railways were identified [15]. Design experiments were used for thermal spraying [16] in 2008, when the critical effective factors affecting the shrinkage porosity of permanent mold casting were evaluated by numerical simulation [17]. Design experiment was also used in 2010 for developing a neural network model to predict the chromium layer thickness in the chromium plating process [18], whereas alkaline cement with a high lime stone content was developed by researchers using design experiments in 2011 [19].

In the present research, the RSM was used for optimization, which includes the following four steps:

Step 1. Designing and performing experiments for obtaining sufficient and reliable criteria for the intended response;

Step 2. Developing mathematical models for firstorder and quadratic response surface with the best correlation;

Step 3. Finding an optimized set of parameters that produce maximum or minimum response values;

Step 4. Evaluating direct and interactive effects of process parameters through the analysis of variance table (ANOVA) [20]. Figure 6 shows the optimization process.

\subsection{Vibration optimization constraints and objective functions of the ERS}

As shown in Figure 6, three parameters are considered for optimization. These parameters include elasticity modulus $A$, width $B$, and height $C$. The suitable range of geometrical variations is set in accordance with CROW (2001) guidelines. The minimum and maximum values of elasticity modulus $A$ are 1 and 10 , respectively, which are selected in accordance with the reference [6]. Given that the objective here is 


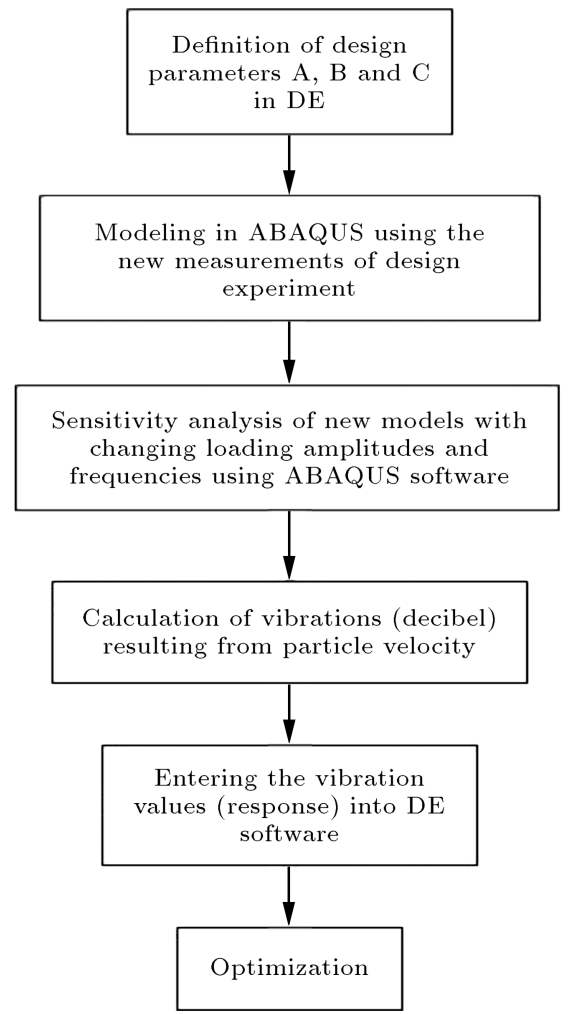

Figure 6. Procedures of the optimization process.

to minimize vibrations, vibration value (decibel) is taken as the objective function; elasticity modulus, width, and height are constraints. Thus, constraints are defined as follows:

$$
\begin{aligned}
& 1 \leq A \leq 10, \\
& 160 \leq B \leq 220, \\
& 110 \leq C \leq 200 .
\end{aligned}
$$

The objective is to achieve the minimum vibration of 65 decibels, which is the allowable value set by FTA [22] shown in Table 3. Thus, the objective function will be given below. In accordance with FTA code of the United States, the vibration value at point $D$ up to point $\mathrm{G}$ (the surrounding environment of the ERS) is 69 decibels, which is 6 percent more than the allowable value of 65 decibels defined by FTA. Here, the objective is to minimize vibrations in accordance with FTA standard. Thus, as may be noted, the vibration value should be reduced to 65 decibels.

$$
d B(X) \leq 65 V d B .
$$

In Eq. (5), dB is the vibration decibel. $X$ represents the intended point, i.e., the vibration decibel at point $X$ should be equal to or less than $65 \mathrm{VdB}$.

\section{Vibration optimization results of the ERS}

Based on the limits specified for constraints as per Central Composite Design (CCD) method, 20 primary experiments were defined, which are equal to the number of models required for the numerical vibration analysis in ABAQUS. Experiments were designed, and the vibration values obtained from the sensitivity analysis aimed at optimization under 1.5 ton loading and frequencies of $35 \mathrm{~Hz}$ are shown in Table 4.

Considering the selected values for the rail such as those of the surrounding compound elasticity modulus, width, and height of the rail (i.e., each row of Table 4), a specific dynamic analysis was carried out by ABAQUS, and the values of vertical vibration velocities were recorded at points $\mathrm{D}$ and $\mathrm{E}$ (in Figure 3 ) in decibel; consequently, these values were considered as

\begin{tabular}{|c|c|c|}
\hline \multirow[t]{2}{*}{ Land use category } & \multicolumn{2}{|c|}{$\begin{array}{l}\text { Ground-borne vibration impact criteria } \\
\text { ( VdB relative to } 1 \mathrm{micro} \text { inch/sec) }\end{array}$} \\
\hline & Frequent events $^{\mathrm{a}}$ & Infrequent events $^{\mathrm{b}}$ \\
\hline $\begin{array}{l}\text { Category 1: Buildings in which vibration interferes with } \\
\text { interior operations }\end{array}$ & $65 \mathrm{VdB}^{\mathrm{c}}$ & $65 \mathrm{VdB}^{\mathrm{c}}$ \\
\hline Category 2: Residences and buildings where people normally sleep & $72 \mathrm{VdB}$ & $80 \mathrm{VdB}$ \\
\hline Category 3: Institutional land uses with primarily daytime use & $72 \mathrm{VdB}$ & $83 \mathrm{VdB}$ \\
\hline \multicolumn{3}{|l|}{${ }^{\mathrm{a}}$ Frequent events are defined as more than 70 vibration events per day. } \\
\hline \multicolumn{3}{|l|}{${ }^{\mathrm{b}}$ Infrequent events are defined to be fewer than 70 vibration events per day. } \\
\hline \multirow{2}{*}{\multicolumn{3}{|c|}{$\begin{array}{l}{ }^{c} \text { This criterion limit is based on the levels that are acceptable for most moderately sensitive equipment such as optical microscope } \\
\text { Vibration-sensitive manufacturing or research will require detailed evaluation to define the acceptable vibration levels. }\end{array}$}} \\
\hline & & \\
\hline \multicolumn{3}{|c|}{$\begin{array}{l}\text { Ensuring lower vibration levels in a building often requires special design of the heating, ventilation, and air conditioning systems, } \\
\text { and stiffened floors. Source: FRA (2005). }\end{array}$} \\
\hline
\end{tabular}
objective functions. Finally, the optimization results were obtained.

Table 3. FRA criteria for the vibrations transferred from the ground [21]. 
Table 4. Primary experiments designed for the optimization of the embedded rail system.

\begin{tabular}{|c|c|c|c|c|c|}
\hline & Factor 1 & Factor 2 & Factor 3 & Response 1 & Response 2 \\
\hline Run & $\begin{array}{c}\text { Elasticity modulus } \\
(\mathrm{MPa})\end{array}$ & Width ( $\mathrm{mm})$ & Height (mm) & $\begin{array}{c}\text { dB } \\
(D) \\
\end{array}$ & $\begin{array}{l}\mathrm{dB} \\
(\mathrm{E}) \\
\end{array}$ \\
\hline 1 & 10 & 160 & 110 & 69.47435 & 65.5581 \\
\hline 2 & 1 & 190 & 155 & 64.15823 & 62.15641 \\
\hline 3 & 1 & 220 & 200 & 64.14935 & 62.31747 \\
\hline 4 & 5.5 & 190 & 155 & 69.55637 & 65.85154 \\
\hline 5 & 1 & 160 & 200 & 63.93899 & 62.23714 \\
\hline 6 & 10 & 220 & 200 & 72.97028 & 65.70232 \\
\hline 7 & 5.5 & 160 & 155 & 70.48184 & 65.57128 \\
\hline 8 & 10 & 190 & 155 & 70.43643 & 65.78223 \\
\hline 9 & 5.5 & 190 & 110 & 71.85597 & 67.04709 \\
\hline 10 & 10 & 160 & 200 & 70.59479 & 67.49189 \\
\hline 11 & 1 & 160 & 110 & 66.17858 & 63.4302 \\
\hline 12 & 5.5 & 190 & 155 & 69.55637 & 65.85154 \\
\hline 13 & 5.5 & 190 & 155 & 69.55637 & 65.85154 \\
\hline 14 & 5.5 & 190 & 200 & 69.2646 & 65.81862 \\
\hline 15 & 5.5 & 190 & 155 & 69.55637 & 65.85154 \\
\hline 16 & 5.5 & 190 & 155 & 69.55637 & 65.85154 \\
\hline 17 & 5.5 & 220 & 155 & 69.96412 & 65.66833 \\
\hline 18 & 5.5 & 190 & 155 & 69.55637 & 65.85154 \\
\hline 19 & 10 & 220 & 110 & 72.51148 & 66.53994 \\
\hline 20 & 1 & 220 & 110 & 65.9758 & 63.5565 \\
\hline
\end{tabular}

5.1. Formulating a mathematical function with effective parameters for the calculation of vibration at critical points

There are some standard design methods for design experiment with the aid of RSM. In this research, CCD method was used for second-order correlation with very good accuracy. This equation was formulated using CCD method. In this method, one can calculate the vibration value (decibel) at points $\mathrm{D}$ and $\mathrm{E}$, once elasticity modulus, width, and height are known. The equation below shows the general form, and Table 5 shows the coefficients used at two critical points of the system.

$$
\begin{aligned}
d B(\text { In target point })= & A+B \times X_{1}+C \times X_{2} \\
& +D \times X_{3}+E \times X_{1} \times X_{2} \\
& +F \times X_{1} \times X_{3}+G \times X_{2} \\
& \times X_{3}+H \times X_{1}^{2}+I \times X_{2}^{2} \\
& +J \times X_{3}^{2},
\end{aligned}
$$

Table 5. Coefficients of design parameters in Eq. (1).

\begin{tabular}{ccccccccccc}
\hline & \multicolumn{10}{c}{ Coefficients of design parameters } \\
\cline { 2 - 12 } Point & A & B & C & D & E & F & G & H & I & J \\
\hline D & 92.79 & 0.58 & -0.18 & -0.14 & $+5 \mathrm{E}-03$ & $+3.48 \mathrm{E}-03$ & $-2.3 \mathrm{E}-05$ & -0.13 & $+4.40 \mathrm{E}-04$ & $+3.62 \mathrm{E}-04$ \\
$\mathrm{E}$ & +58.42 & +1.19 & +0.098 & -0.073 & -0.073 & $-9.39 \mathrm{E}-04$ & $-2.61 \mathrm{E}-04$ & -0.09 & $-1.42 \mathrm{E}-04$ & $+3.38 \mathrm{E}-04$ \\
\hline
\end{tabular}


where $X_{1}, X_{2}$, and $X_{3}$ are the elasticity modulus, width, and height of the rail, respectively, and the target point is $\mathrm{E}$ or $\mathrm{D}$. As is obvious, variations in vibrations (decibel) with respect to the width, height, and elasticity modulus as design parameters have the quadratic form.

\subsection{Variance Analysis (ANNOVA)}

Table 6 shows variance analysis of model parameters in the order of their importance. The significance threshold is assumed $0.05(5 \%)$ in here. This coefficient determines the probability of error in the model. In other words, the probability of error is 5 percent in this mode. The $p$-value should be less than the significance coefficient so that the intended factor equals a significant value. A $p$-value less than 0.0001 in ANOVA makes it significant, which may be seen in the first row of the table below. $B C$ and $B^{2}$ parameters are significant only.

\subsection{Checking the optimization results for 1.5-ton loading at a frequency of $35 \mathrm{~Hz}$}

Given that the objective is to minimize the system vibrations produced in the surrounding environment,

Table 6. ANOVA for response surface quadratic model.

\begin{tabular}{ccc}
\hline Model & $\boldsymbol{F}$-value & $\begin{array}{c}\boldsymbol{p} \text {-value } \\
\text { Prob }>\boldsymbol{F}\end{array}$ \\
\cline { 2 - 3 } & $\mathbf{4 4 . 0 4 6 3 4}$ & $<\mathbf{0 . 0 0 0 1}$ \\
\hline A-elasticity modulus & 298.5853 & $<0.0001$ \\
B-width & 7.192771 & 0.0230 \\
C-height & 7.717591 & 0.0195 \\
AB & 10.92893 & 0.0079 \\
AC & 11.92205 & 0.0062 \\
BC & 0.023098 & 0.8822 \\
$\mathrm{~A}^{2}$ & 52.65692 & $<0.0001$ \\
B $^{2}$ & 1.291845 & 0.2822 \\
$\mathrm{C}^{2}$ & 4.427854 & 0.0616 \\
\hline
\end{tabular}

a vibration value of 65 decibels was considered as the maximum vibration transferred to the environment in accordance with FTA (2006) code. The optimization result of 1.5-ton loading at a frequency of $35 \mathrm{~Hz}$ is given in Table 7.

As can be seen in Table 7, the optimization results of a 1.5-ton wheel load at a frequency of $35 \mathrm{~Hz}$ are shown in Table 7 . Ten optimum cases are presented in the table, and the selected model by the software is shown in the first row of the table.

\subsubsection{Optimization results}

Optimization results are shown in various ways in Figures 7 and 8 . Figures 7,8 show the anticipated vibration lines of the model. In these figures, the predicted response values are shown in the abovementioned loading conditions in case 1 of Table 4. Dark blue zones show the predicted value of optimization, and other zones show higher values. In fact, we can see the vibration values (in decibel) at these points, which are obtained as a result of optimization. These values correspond to the lowest vibration values produced by the system.

As can be seen in Figure 9, changes in the width do not affect the suitability of responses at low height values. However, the suitability of responses increases with the height. The peak point of this diagram corresponds to higher heights and increased widths. Hence, at constant, high heights, the suitability of responses increases with the width. ANOVA table shows the importance of the height/width ratio.

According to Figure 10, the suitability level does not change with an increase in elasticity modulus. However, for elasticity modulus below $2 \mathrm{MPa}$, the suitability level increases significantly. Therefore, the importance of elasticity modulus versus height may be clearly seen, as shown in ANOVA table. In fact, system desirability tends to increase with a reduction in elasticity modulus and an increase in height. However, for higher parameter values, the system desirability

Table 7. Optimization results for a 1.5-ton loading at a frequency of $35 \mathrm{~Hz}$.

\begin{tabular}{ccccccc}
\hline Case no. & Elasticity modulus & Width & Height & dB_D & dB_E & Desirability \\
\hline 1 & 1 & 204.10 & 189.64 & 63.4661 & 62.0431 & 0.532 \\
2 & 1 & 204.37 & 189.68 & 63.4675 & 62.0405 & 0.532 \\
3 & 1 & 203.86 & 189.46 & 63.4652 & 62.0449 & 0.532 \\
4 & 1 & 204.65 & 189.17 & 63.4704 & 62.0354 & 0.532 \\
5 & 1 & 203.78 & 190.42 & 63.4629 & 62.0501 & 0.532 \\
6 & 1 & 205.41 & 189.96 & 63.4733 & 62.0304 & 0.532 \\
7 & 1 & 202.6 & 189.82 & 63.4586 & 62.0595 & 0.532 \\
8 & 1 & 195.4 & 186.24 & 63.4631 & 62.1054 & 0.527 \\
9 & 1 & 194.53 & 184.47 & 63.4743 & 62.1047 & 0.525 \\
10 & 1.02 & 204.63 & 188.83 & 63.502 & 62.0533 & 0.525 \\
\hline
\end{tabular}


Design-Expert ${ }^{\circledR}$ Software Factor Codin: Actual dB_D

72.9703

63.939

$\mathrm{X} 1=\mathrm{A}:$ Elasticity module $\mathrm{X} 2=\mathrm{B}:$ Width

Actual factor

C: Height $=189.62$

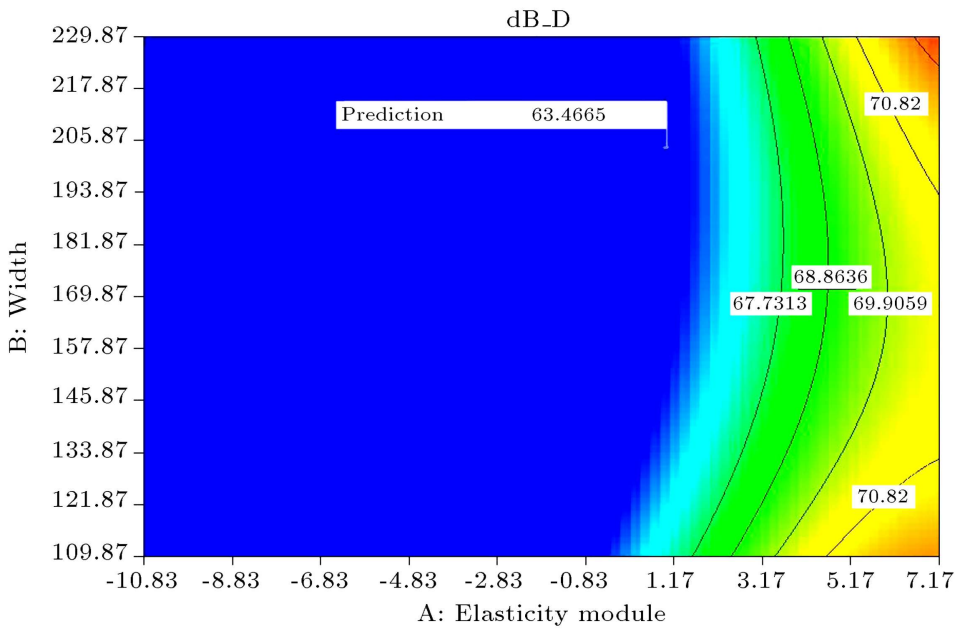

A: Elasticity module

Figure 7. Vibration(decibel) at point D and width to elasticity modulus at a constant height of $189.62 \mathrm{~mm}$.

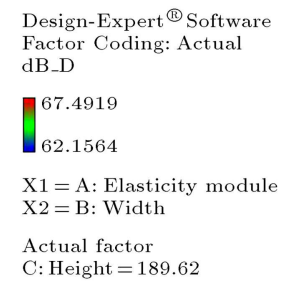

Design-Expert ${ }^{\circledR}$ Software dB_D

62.1564

C: Height $=189.62$

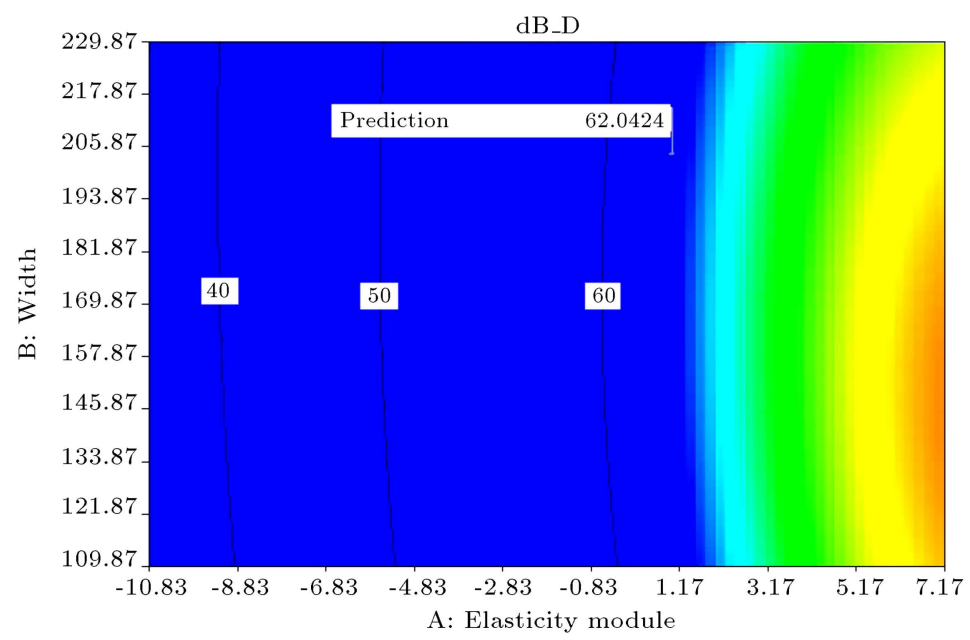

Figure 8. Vibration diagram at point $\mathrm{E}$ and width to elasticity modulus at a constant height $189.62 \mathrm{~mm}$.

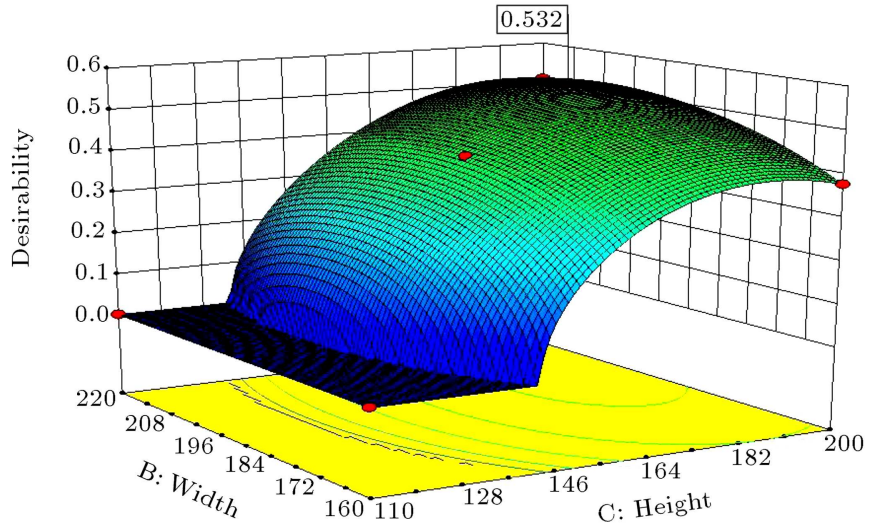

Figure 9. 3D level-suitability of responses with a constant elasticity modulus. is a factor or a height involving a value of elasticity modulus.

Similar to Figure 10, Figure 11 shows that, for the modulus of elasticity values to be less than $2 \mathrm{MPa}$, the desirability increases with the width. However, at higher values of elasticity modulus, variations in the width do not affect system desirability. In fact, elasticity modulus is a more important parameter in design than the width of elastic compound, which can be seen in the ANOVA table. 
Design-Expert ${ }^{\circledR}$ Software Factor Coding: Actual Desirability

๑ $\begin{aligned} & 1.000 \\ & 0.000\end{aligned}$

$\mathrm{X} 1=\mathrm{A}:$ Elasticity module $\mathrm{X} 2=\mathrm{C}$ : Height

Actual factor

B: Width $=204.12$

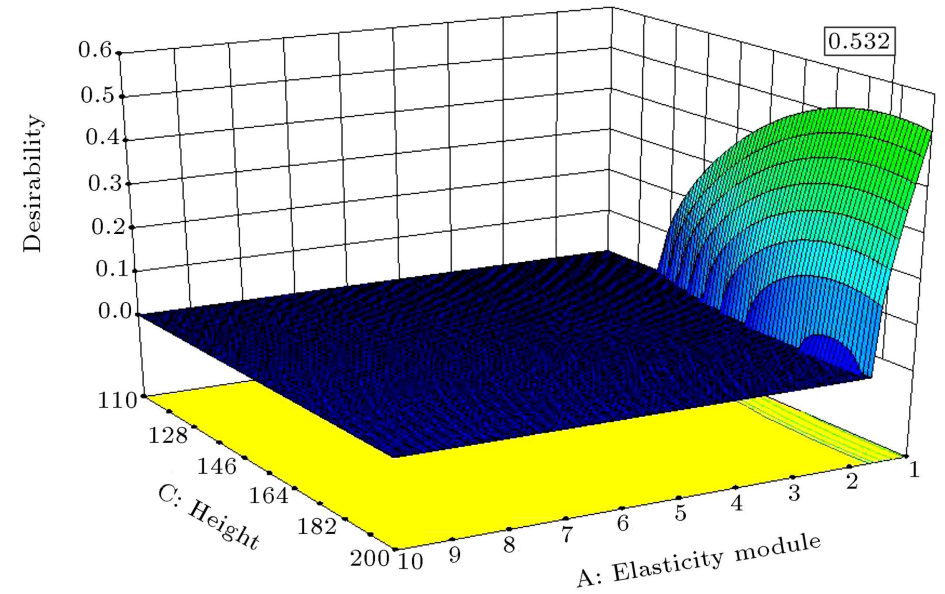

Figure 10. 3D level-suitability of responses with a constant width.
Design-Expert ${ }^{\circledR}$ Software Factor Coding: Actual Desirability

$\prod_{0.000}^{1.000}$

$\mathrm{X} 1=\mathrm{A}$ : Elasticity module $\mathrm{X} 2=\mathrm{B}:$ Width

Actual factor

C: Height $=189.69$

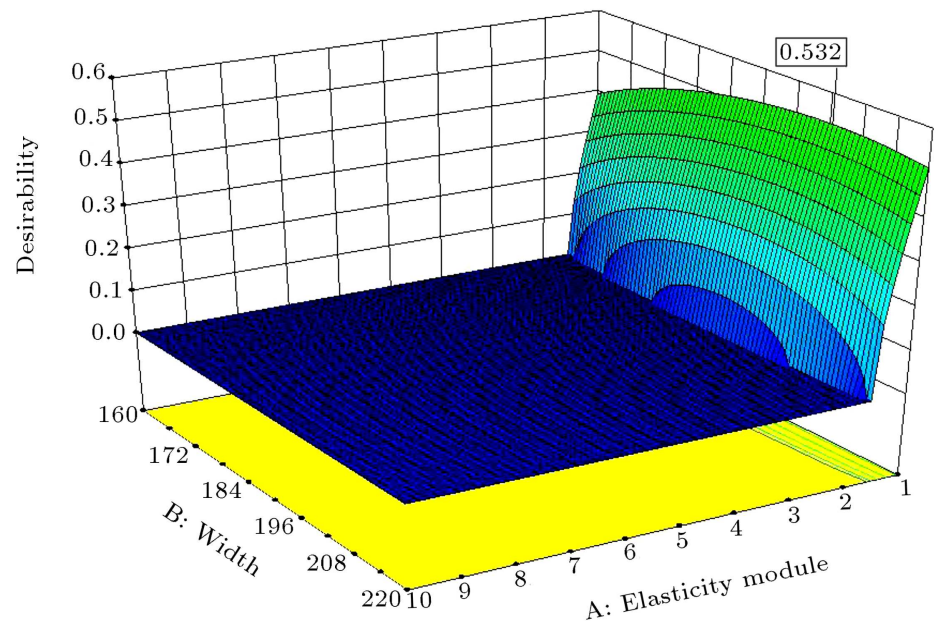

Figure 11. 3D level-suitability of responses with a constant height.

\subsection{Optimization results for all loadings}

Optimization of the 1.5-ton load at a frequency of 35 $\mathrm{Hz}$ using Design Expert (DE) software was described in the previous sections. Given the excessive results and various loading conditions and frequencies of these models, the optimization of other models is given briefly in Table 8 .

Considering the table above, vibration may not be reduced to 65 decibels in all loading conditions. "Minimize Column" shows the vibration (decibel) of the system under various loading and frequencies. As can be seen, frequency increase produced better results when a 1.5-ton wheel load was applied. Thus, vibrations could be reduced to 65 decibels for higher frequencies. However, these conditions change with an increase in loadings as they produce different results under higher loads. For instance, under conditions with a 5-ton load and frequency of $5 \mathrm{~Hz}$, the maximum vibration is significantly higher than the vibration produced at this frequency with 9 -ton wheel load.

\section{Summary and conclusion}

In this paper, the Embedded Rail System (ERS) was modeled statically using the finite element software ABAQUS; then, it was compared with the research undertaken by Esveld et al., showing a negligible difference. Then, this numerical model was developed for a vibration analysis. Vertical dynamic loads were applied to the model, and the results of vibration (decibel) were obtained for various loadings using the design experiment method with the aid of Design Expert (DE) software. This research is aimed at minimizing the environmental vibrations by optimizing the trough geometry of the rail and properties of surrounding elastic compounds. Considering the experiments designed for the width, height, and elasticity modulus of the compound, the following optimization results were obtained:

- Considering the investigations made in the optimization process, it was revealed that elasticity modulus was the most effective parameter in producing vibration. Increases in this parameter resulted in 
Table 8. Optimization results of various loadings and the lowest vibration (decibel) for various loads and frequencies.

\begin{tabular}{|c|c|c|}
\hline \multicolumn{2}{|c|}{ Model } & \multirow{2}{*}{$\begin{array}{l}\text { Optimum design } \\
\text { Minimum value }\end{array}$} \\
\hline $\begin{array}{c}\text { Wheel load } \\
\text { (ton) }\end{array}$ & $\begin{array}{c}\text { Frequency } \\
\left(\mathrm{Hz}_{\mathrm{z}}\right)\end{array}$ & \\
\hline \multirow{4}{*}{1.5} & 5 & 83 \\
\hline & 20 & 70 \\
\hline & 35 & 65 \\
\hline & 50 & 65 \\
\hline \multirow{4}{*}{5} & 5 & 95 \\
\hline & 20 & 75 \\
\hline & 35 & 70 \\
\hline & 50 & 75 \\
\hline \multirow{4}{*}{9} & 5 & 75 \\
\hline & 20 & 80 \\
\hline & 35 & 80 \\
\hline & 50 & 75 \\
\hline
\end{tabular}

more vibrations, and lower values of this parameter led to greater system desirability. When the elasticity modulus value is high (approx. in excess of $7 \mathrm{MPa}$ ), increasing or decreasing the height of elastic compound will not have significant effect on the reduction of vibrations;

- After elasticity modulus, the effect of elastic compound height on the vibration level was significant. An increase in the height decreased vibrations. When the elasticity modulus of elastic compound was low (2 $\mathrm{MPa}$ or less), an increase in the height of elastic compound reduced vibrations;

- The width parameter, like the height parameter, had inconsiderable effects on the vibrations. At a low elasticity modulus value, an increased width did not produce high vibration values. At lower heights, changes in the width did not affect the system desirability. However, the system desirability increased with the height. At higher heights, the model desirability decreased with the width. Moreover, at low elasticity modulus values, the vibrations tend to decrease with an increase or a decrease in the width;

- As shown in ANOVA, the interaction of elasticity modulus with the height was the most effective parameter in the level of vibrations (decibel). According to the results, when the height parameter changes occurred in the range of $110-220 \mathrm{~mm}$, an increase in elasticity modulus increased the vibration level. At lower heights, an increase in elasticity modulus produced more vibrations than higher heights. For an elasticity modulus equivalent to $10 \mathrm{MPa}$, the vibration values at the upper and lower limits were the same;
- There were no interactions between the width and height parameters found. As can be noted in ANOVA, the interaction between these two parameters was of the lowest importance with the least effects in the optimization process. In fact, for an elasticity modulus of 2 or less than $2 \mathrm{MPa}$, increasing the width and height of elastic compounds did not have any significant effects on the level of vibrations.

\section{References}

1. Center for Regulation and Research in Soil, Water and Road Construction and Traffic Engineering (CROW), Recommendations and Guidelines for Embedded Rail Systems, pp. 1-54 (2001).

2. Esveld, C. "Chair for railway engineering", Annual Report, Report Period (1998).

3. Esveld, C., Tolboom, A.G., and de Man, A.P. "Stability of embedded rail structures", Theoretical Investigation HSL-South (in Dutch), Report 7-97-120-5, TUD/Rbk (1998).

4. Suiker, A.S.J. "Fatigue behavior of granular materials", Part I: Constitutive modeling and description of experiments, Report 7-97-119-2, TUD/Rbk and Part 2: Numerical formulation of the constitutive relations, Report 7-98-119-3, TUD/Rbk (1997 \& 1998).

5. Markine, V.L., Annual Report, Section of Road and Railway Engineering - Report 7-06-110-26 ISSN 01699288 (2006).

6. Ludvigh, E. "Elastic behaviour of continuously embedded rail systems", Periodica Polytechnica Civil Engineering, 46, pp. 103-114 (2002).

7. Esveld, C., Markine, V.L., de Man, A.P., and Jovanovic, S., Optimum Design of Embedded Rail Structure for High-Speed Lines, Section of Road and Railway Engineering Faculty of Civil Engineering, Delft University of Technology (2003).

8. Eisenmann, J. and Leykauf, G. "Feste Fahrbahnen für Schienenbahnen", Beton-Kalendere, Teil 2, S., pp. 291-326 (2000).

9. Degrande, G. and Schillemans, L. "Free field vibrations during the passage of a Thalys high-speed train at variable speed", Journal of Sound and Vibration, 247(1), pp. 131-144 (2001).

10. ISO 2041, Vibration and Shock - Vocabulary (1990).

11. Telford, J.K. and Hopkins, J. "A brief introduction to design of experiments", Johns Hopkins APL Technical Digest, 27(3), pp. 224-232 (2007).

12. Lye, L.M. "Design of experiments in civil engineering: Are we still in the 1920s?", Annual Conference of the Canadian Society for Civil Engineering, GE069, pp. 1-10 (2002). 
13. Yeh, I. "Analysis of strength of concrete using design of experiments and neural networks", American Society Of Civil Engineers (ASCE), 18(4), pp. 597-604 (2006).

14. Yahia, A. and Khayat, K.H. "Experiment design to evaluate interaction of high-range water-reducer and antiwashout admixture in high-performance cement grout", Cement and Concrete Research, 31, pp. 749757 (2001).

15. Choudhury, S.K. and Bartarya, G. "Role of temperature and surface finish in predicting tool wear using neural network and design of experiments", International Journal of Machine Tools \& Manufacture, 43, pp. 747-753 (2003).

16. Brown, S.F., Kwan, J., and Thom, N.H. "Identifying the key parameters that influence geogrid reinforcement of railway ballast", Geotextiles and Geomembranes, 25(6), pp. 326-335 (2007).

17. Pierlot, Ch., Pawlowski, L., Bigan, M., and Chagnon, P. "Design of experiments in thermal spraying: A review", Surface \& Coatings Technology, 202(18), pp. 4483-4490 (2008).

18. Gunasegaram, D.R., Farnsworth, D.J., and Nguyen, T.T. "Identification of critical factors affecting shrinkage porosity in permanent mold casting using numerical simulations based on design of experiments", Journal of Materials Processing Technology, 209(3), pp. 1209-1219 (2009).

19. Sánchez Lasheras, F., VilánVilán, J.A., García Nieto, P.J., and del Coz Díaz, J.J. "The use of design of experiments to improve a neural network model in order to predict the thickness of the chromium layer in a hard chromium plating process", Mathematical and Computer Modeling, 52, pp. 1169-1176 (2010).

20. Moseson, A.J., Moseson, D.E., and Barsoum, M.W. "High volume limestone alkali-activated cement developed by design of experiment", Cement \& Concrete Composites, 34, pp. 328-336 (2012).

21. Montgomery, D.C. and Runger, G.C., Applied Statistics and Probability for Engineers, In John Wiley \& Sons Inc, Third Edition, New York (2003).

22. Hanson, C.E., Towers, D.A., and Meister, L.D., Transit Noise and Vibration Impact Assessment, U.S.
Department of Transportation Federal Transit Administration Office of Planning and Environment, S.E. Washington, FTA-VA-90-1003-06 (2006).

\section{Biographies}

Morteza Esmaeili obtained his BS degree from the Department of Civil Engineering at Iran University of Science and Technology (IUST), Tehran, Iran and, then, received $\mathrm{MS}$ and $\mathrm{PhD}$ degrees in Geotechnical Engineering from the University of Tehran (UT), Tehran, Iran. He is currently an Associate Professor at the School of Railway Engineering at Iran University of Science and Technology (IUST), Tehran, Iran. His key research interests and areas of expertise include track geo-technology, mechanics of porous media, train induced vibration, and design of ballast-less tracks. He has also published five books in different fields consisting of bridge substructure design, TBM tunneling, railway track geo-technique, soil steel bridges, and ballast-less tracks.

Masoud Yaghini received the $\mathrm{PhD}$ degree in Rail Transportation Planning and Engineering from the Beijing Jiaotong University of China in 2002. He joined the School of Railway Engineering of Iran University of Science and Technology as an Assistant Professor and became an Associate Professor in 2014. His current research interests include rail transportation planning, optimization techniques, and data mining techniques.

Shila Moslemipour received her BS degree in Civil Engineering from Iran University of Science and Culture, Tehran, Iran, 2010 and MS degree in Railway Engineering from Iran University of Science and Technology (IUST), Tehran, Iran, 2013. Her research interests include optimization of embedded rail slab track with respect to the environmental vibrations using ABAQUS and Design Of Experiment (DOE). 